\title{
SIMPLE ESTIMATION OF GRANULE SIZE DISTRIBUTION AND SLUDGE BED POROSITY IN A UASB REACTOR
}

\author{
A.G. VLYSSIDES* \\ E.M.P. BARAMPOUTI \\ S.T. MAI
}

\author{
School of Chemical Engineering \\ National Technical University of Athens \\ 9 Heroon Polytechniou Str. \\ Zographou, Athens, 15700, Greece
}

Received: 05/10/07

Accepted: 10/12/07 *to whom all correspondence should be addressed:

Fax. +30 210 7723269; e-mail: avlys@tee.gr

\begin{abstract}
Granular sludge is the key factor for an efficient operation of an upflow anaerobic sludge blanket (UASB) reactor. In order to monitor the granularity of anaerobic sludge, the determination of the granule size distribution is of vital importance. Another critical parameter for the UASB reactor performance is the sludge bed porosity. For this reason, several techniques have been proposed, however they are either tedious, imprecise or expensive and hardly applicable in full scale treatment plants. There was then the need for a simple and low cost technique. This technique involves the determination of the settling velocities of a sludge sample and of extrapolating the corresponding diameters using a mathematical algorithm. In the proposed algorithm, the granules density was calculated, the flow regime was examined and finally the granule size distribution was obtained. Some very important correlations were suggested by the experimental results. The granule density and diameter as well as the sludge bed porosity were strongly correlated with the VSS/TSS ratio.
\end{abstract}

KEYWORDS: UASB, granule size distribution, granule diameter, granule density, sludge bed porosity, VSS/TSS ratio

\section{INTRODUCTION}

The last 20 years, many full scale upflow anaerobic sludge blanket (UASB) reactors have been constructed to treat industrial wastewater. The limitations of UASB reactors are related to the wash-out of biomass. So, the granulation process is a pre-requisite of a UASB system start-up and operation. The treatment capacity of a UASB system depends on whether granulation is accomplished with particular operating conditions, e.g. wastewater composition, organic loading rate, temperature, etc (Jeison and Chamy, 1998; Xu and Tay, 2001). The quality and stability of sludge directly dictates the behaviour of the entire treatment system. One of the most important characteristics is their size distribution. This size with their density, defines the settling properties of the sludge, attribute that is fundamental from the operational point of view (Jeison and Chamy, 1998).

To date, three techniques are routinely used to determine the particle size distribution of UASB sludge. Two of them consist in the direct size measurement with a microscope of at least 100 sludge granules immobilized in a petri dish. This can be done either manually with a porton graticule or automatically using image analysis and computerized data processing (Hulshoff Pol, 1989; Dudley et al., 1993). The last method involves particle size analysis by laser and has been introduced in the late '90s (Yan and Tay, 1997). Unfortunately all these procedures present several disadvantages. The graticule one is very tedious while the image and laser analysis are expensive (at least \$US 10000 for image analysis and between 30 000 and 60000 for the laser one). Finally, none of the previous techniques, because of their complexity or cost can be easily set up in treatment plants and as a consequence are almost confined to laboratory studies (Laguna et al., 1999). 
It is therefore of great importance to have a technique that allows the evaluation, in a reliable and reproducible way, of the size distribution of anaerobic granular sludge. This paper presents a way to evaluate the sludge size distribution using settling velocities of a sludge sample and extrapolating the corresponding diameters.

\section{MATERIALS AND METHODS}

\subsection{Source of granular sludge}

In the present investigations, the physical properties of anaerobic granular sludges cultivated on different types of wastewater and coming from four different UASB reactors were determined and compared. The granular sludge samples tested were:

- Granular sludge cultivated on wastewater from a potato processing industry

- Granular sludge cultivated on dairy wastewater with iron addition

- Granular sludge cultivated on dairy wastewater with calcium addition

- Granular sludge cultivated on dairy wastewater

The choice of the sludges ensured a wide range of sludge composition and physical characteristics.

\subsection{Granule density measurement}

The granule density was determined with a picnometer according to the method of Mahling (1965). This density measurement was performed at $30{ }^{\circ} \mathrm{C}$ using $25 \mathrm{ml}$ flasks with glass stoppers with capillars. The granule density $\left(\rho_{p}\right)$ was calculated according to the equation 1 (Hulshoff Pol, 1989):

$\rho_{\mathrm{p}}=\left(\rho_{\mathrm{w}}-\rho_{\mathrm{a}}\right) \frac{\mathrm{m}_{3}-\mathrm{m}_{1}}{\left(\mathrm{~m}_{2}-\mathrm{m}_{1}\right)-\left(\mathrm{m}_{4}-\mathrm{m}_{3}\right)}+\rho_{\mathrm{a}}$

in which:

$\rho_{a}=$ the density of the air $\left(\mathrm{kg} \mathrm{m}^{-3}\right)$, which is 1,165 at $30^{\circ} \mathrm{C}$ and a $P_{\text {atm }}$ of $760 \mathrm{~mm} \mathrm{Hg}$

$\mathrm{m}_{1}=$ weight of the empty picnometer $(\mathrm{kg})$

$\mathrm{m}_{2}=$ weight of the picnometer filled with water $(\mathrm{kg})$

$\mathrm{m}_{3}=$ weight of the picnometer filled with sludge $(\mathrm{kg})$

$\mathrm{m}_{4}=$ weight of the picnometer filled with water and sludge $(\mathrm{kg})$

$\rho_{\mathrm{w}}=$ the density of water $\left(\mathrm{kg} \mathrm{m}^{-3}\right)$, which is $=995,85$ at $30^{\circ} \mathrm{C}$.

\subsection{Upflow velocity test}

The settling properties of granules were evaluated by the fractions of granules exited under certain upflow velocities in a fractionating device (Figure 1) (Andras et al., 1989).

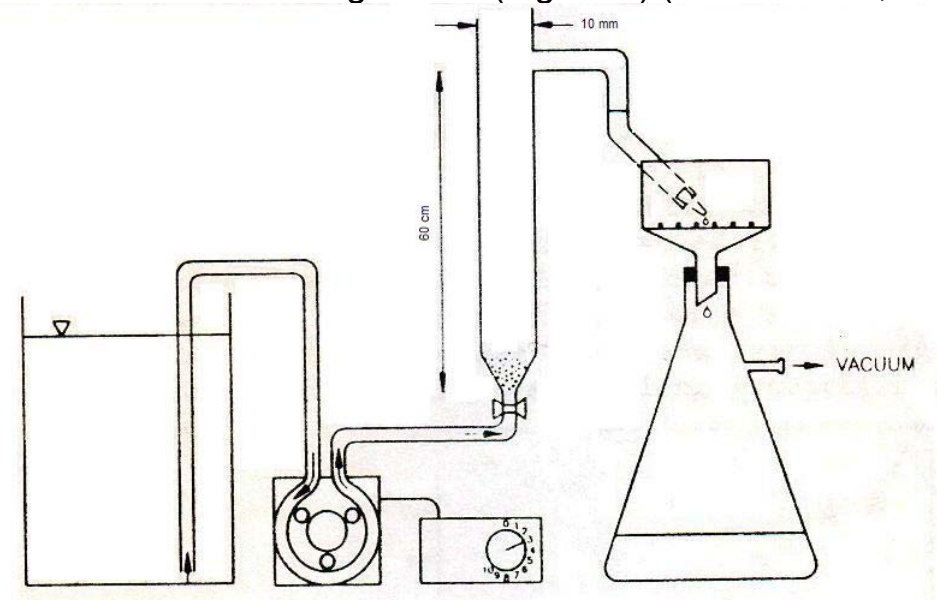

Figure 1. Upflow velocity test apparatus

About $8 \mathrm{ml}$ of granules from the reactor were separated into ten fractions under upflow liquid velocities of 1,8, 2,2, 3,4, 5,1, 10,7, 16,8, 21,1,30,9, 46,6, 99,6 $\mathrm{m}^{-1}$ respectively and at each velocity for $5 \mathrm{~min}$. Each fraction from the fractionating device was collected in a Whatman 
(1PS) filter paper. TSS and VSS in each fraction were determined using the method described by Andras et al. (1989).

The analysis for TSS and VSS were conducted in accordance with the standard methods (APHA, 1985).

\section{RESULTS}

\subsection{Granule density}

400 sludge samples from the four UASB reactors operating under different conditions (e.g. loading rate, metal addition, temperature) were collected for a period of two months. For these samples, the total and volatile suspended solids concentrations as well as their density were determined. Each measurement was repeated three times and the results presented are the mean values. The standard deviations of total and volatile suspended solids concentrations were 5 and $6 \%$ respectively. Regarding the standard deviation of density, it was $10 \%$.

A significant correlation $\left(R^{2}=0,968\right)$ between the granule density and the ratio VSS/TSS of the sludge arose (Equation 2).

$\rho_{\mathrm{p}}=1387-3,77 \frac{\mathrm{VSS}}{\mathrm{TSS}}$

in which

$\frac{\text { VSS }}{\text { TSS }}=$ the $\%$ percentage of volatile suspended solids

Figure 2 presents the densities measured experimentally for the 400 different sludge samples and the respective densities predicted by equation 2 .

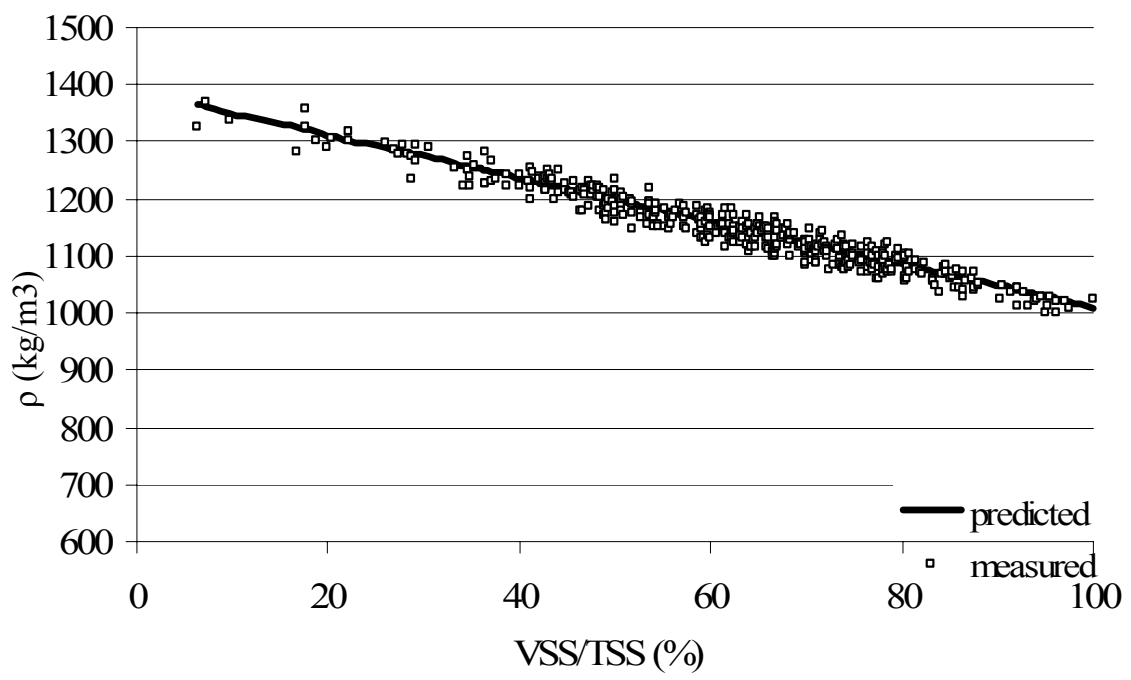

Figure 2. Correlation of densities with VSS/TSS ratio

\subsection{Settling properties of granular sludge}

For 100 sludge samples, the upflow velocity test was performed, and VSS, TSS concentrations of every fraction were determined. A settling velocity profile of each particular sample can be depicted by plotting upflow velocity versus percent of TSS lost from the glass test device (Figure 3a). A plot of cumulative percent of TSS lost from the glass test device versus upflow velocity is more revealing and an easier way to interpret the results (Figure $3 b$ ). Figures such as Figures $3 \mathrm{a}$ and $3 \mathrm{~b}$ were plotted for each of the 100 samples examined. 
(a)

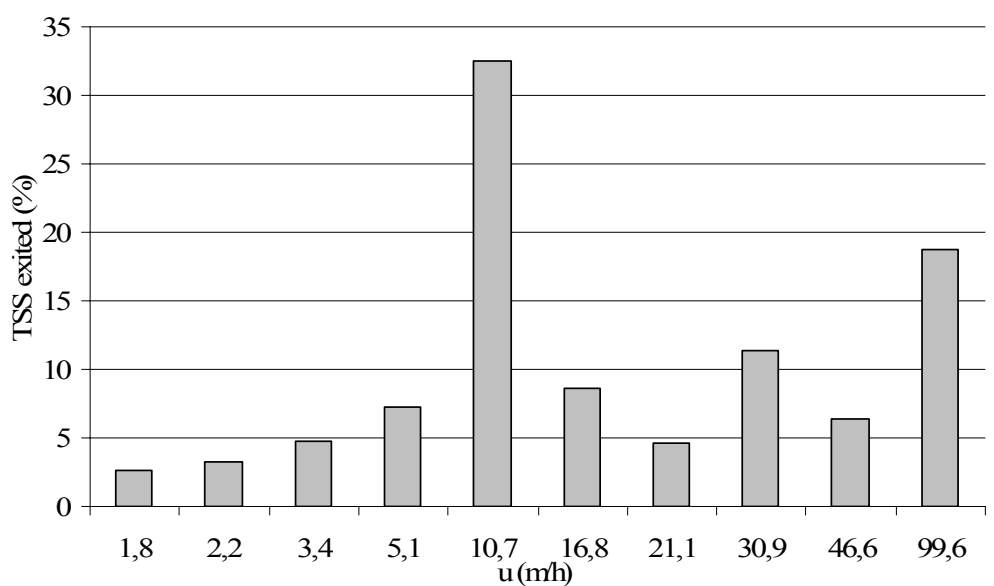

(b)

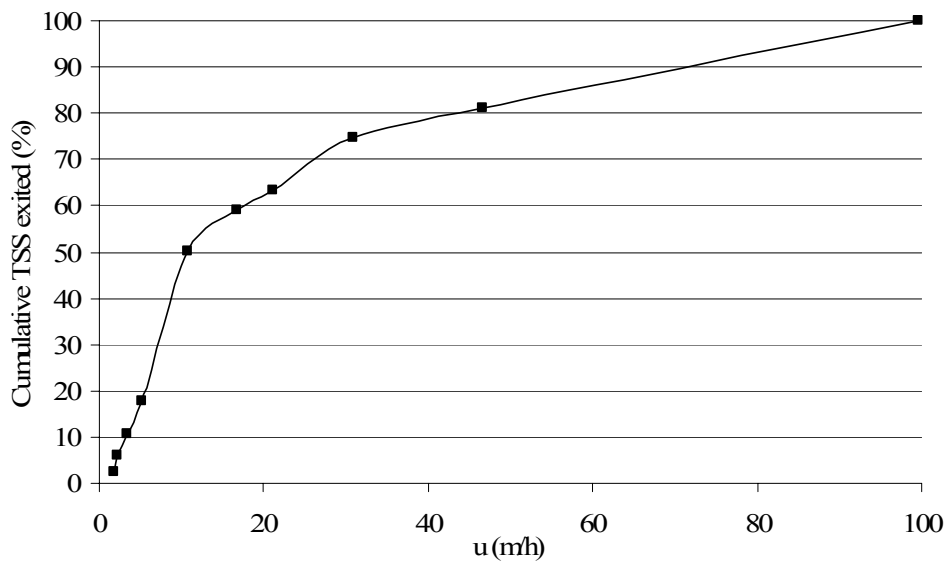

Figure 3. Upflow velocities profile (a) and cumulative solids loss plot (b) for a typical sludge sample

A mathematical algorithm was developed in order to estimate the size distribution of a sludge sample from the upflow velocity and the VSS/TSS ratio of each fraction, assuming spherical granules. Given the upflow velocities, the diameter of each fraction, may be estimated, after a looping procedure, from the following equations $3-5$ (Metcalf \& Eddy, 1991) taking into account the flow regime.

For laminar flow $(\operatorname{Re}<0,5)$

$$
d=\left[\frac{18 u v}{g\left(\rho_{p} / \rho_{w}-1\right)}\right]^{0,5}
$$

For transient flow $\left(0,5<\operatorname{Re}<10^{5}\right)$

$$
d=\frac{3 u^{2} C_{D}}{4 g\left(\rho_{p} / \rho_{w}-1\right)}
$$

For turbulent flow $\left(\operatorname{Re}>10^{5}\right)$

$$
d=\frac{0,3 u^{2}}{g\left(\rho_{p} / \rho_{w}-1\right)}
$$

where

$\mathrm{d}=$ granule diameter $(\mathrm{m})$

$\mathrm{u}=$ upflow velocity $\left(\mathrm{m} \mathrm{s}^{-1}\right)$

$v=$ kinematic viscosity $\left(\mathrm{m}^{2} \mathrm{~s}^{-1}\right)$, which is $=8,01 \cdot 10^{-7}$ at $30^{\circ} \mathrm{C}$

$\mathrm{g}=$ gravitational acceleration $\left(9,81 \mathrm{~m} \mathrm{~s}^{-2}\right)$ 
$\operatorname{Re}=$ Reynolds number

$C_{D}=$ Drag coefficient, which can be calculated by $C_{D}=\frac{24}{R e}+\frac{3}{R^{0,5}}+0,34$

for transient flow.

For the diameter calculation, the value of granule density $\left(\rho_{p}\right)$ is necessary, so equation 2 was indispensable.

For the typical sludge sample presented in Figure 3, the corresponding size distribution is depicted in Figure 4. It is evident that by a simple settleability test, the size distribution of a sludge sample may be obtained avoiding tedious, imprecise and expensive tests, such as microscope sizing, image and laser analysis.

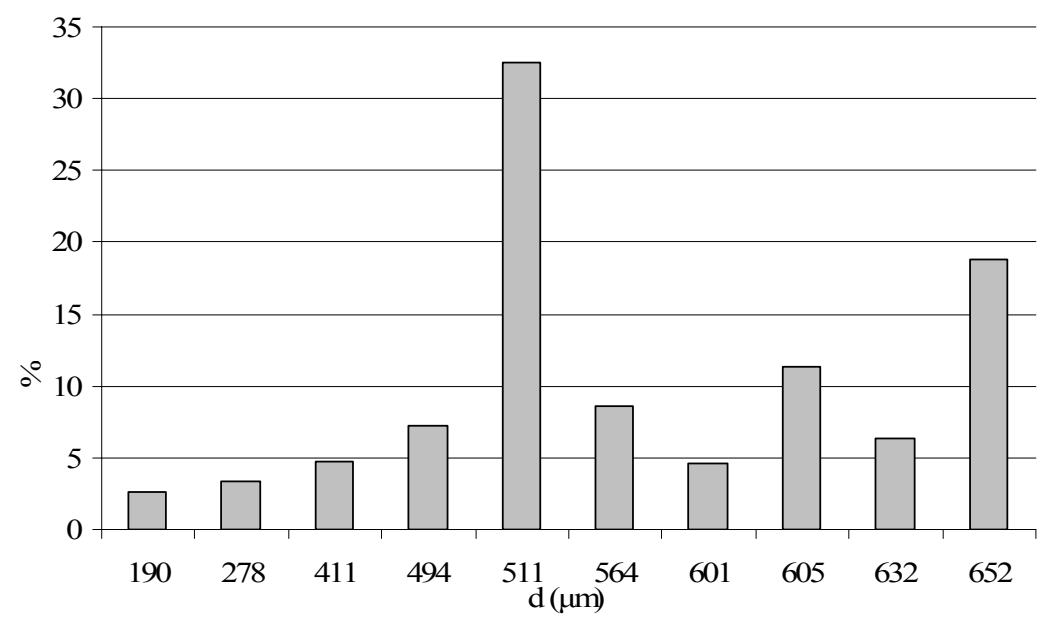

Figure 4. Particle size distribution for a sludge sample

After processing the experimental results of the upflow velocity test, the size distribution of all samples came up. This revealed a significant correlation between the granule diameter and the ratio VSS/TSS. Equation 7 depicts this correlation $\left(R^{2}=0,975\right)$ :

$d=-8 \times 10^{-4} \log \left(1-\frac{V S S / T S S}{97,27}\right)$

Figure 5 presents the granule diameters estimated from experimental data for the different sludge samples and the respective diameters predicted by equation 7 .

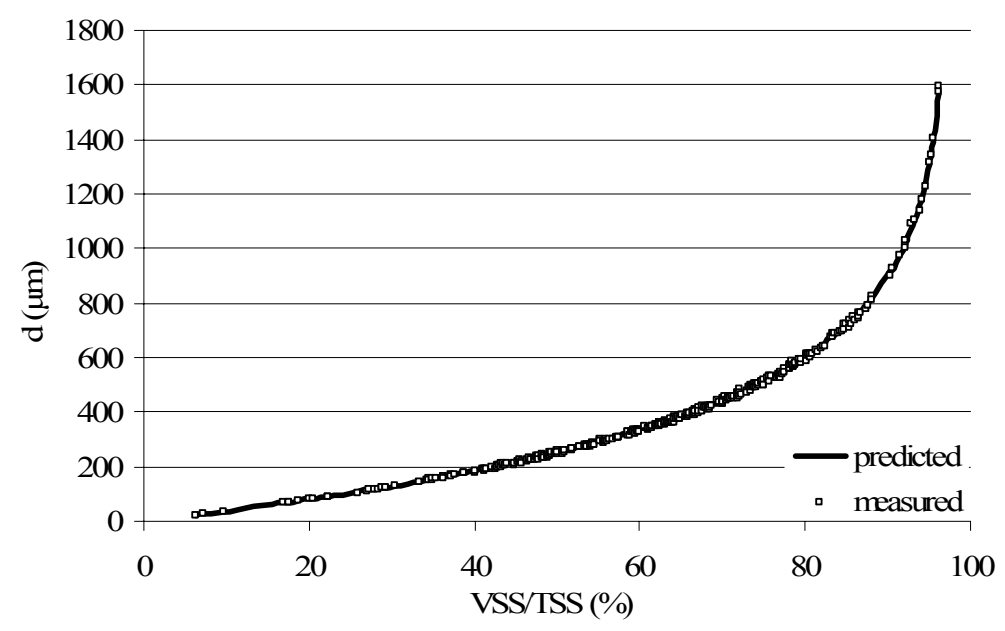

Figure 5. Correlation of granule diameter with VSS/TSS ratio 


\subsection{Sludge bed porosity}

For the estimation of sludge bed porosity, $\varepsilon$, the algorithm suggested by Elmaleh and Grasmick (1985) for biological sludge granules with inert nuclei was used. According to them, the porosity of the sludge bed can be estimated by the equation 8 .

$\varepsilon=\left[\frac{18 \operatorname{Re}+2,7 \operatorname{Re}^{1,69}}{A r}\right]^{1 / 4,7}$

where Re: Reynolds number for a particle

Ar: Archimedes number

$\operatorname{Re}=\frac{\rho u_{\mathrm{up}} \mathrm{d}}{\mu}$

$\operatorname{Ar}=\frac{\rho g\left(\rho_{\mathrm{p}}-\rho\right) \mathrm{d}^{3}}{\mu^{2}}$

where $\rho$ the liquid's density $\left(\mathrm{kg} \mathrm{m}^{-3}\right)$

$\rho_{\mathrm{p}}$ the density of a spherical particle $\left(\mathrm{kg} \mathrm{m}^{-3}\right)$

$\mathrm{d}$ the diameter of a spherical particle $(\mathrm{m})$

$\mathrm{u}_{\mathrm{up}}$ the upflow velocity of the liquid $\left(\mathrm{m} \mathrm{s}^{-1}\right)$

$\mu$ the dynamic viscosity of the flowing liquid $\left(\mathrm{kg} \mathrm{m}^{-1} \mathrm{~s}^{-1}\right)$

$\mathrm{g}$ the acceleration constant $\left(=9,81 \mathrm{~m} \mathrm{~s}^{-2}\right)$.

For the calculation of the sludge bed porosity $(\varepsilon)$ of the UASB reactor the equations above were used where it was assumed that the liquid of the bioreactor behaved as water. Thus, it is $\rho=995 \mathrm{~kg} \mathrm{~m}^{-3}, \mu=8,777 \times 10^{-4} \mathrm{~kg} \mathrm{~m}^{-1} \mathrm{~s}^{-1}$. The upflow velocity of the liquid in all experiments was kept constant and equal to $1 \mathrm{~m} \mathrm{~h}^{-1}$. In Figure 6 the correlation of sludge bed porosity with the VSS/TSS ratio is presented. The values described as "measured" in Figure 6 were calculated using the experimentally measured values of granule density and diameter, whereas the values described as "predicted" arose by use of equations 2 and 7 and VSS/TSS as the only input value. From Figure 6, it is clear that "measured" and "predicted" values of sludge bed porosity are in good agreement.

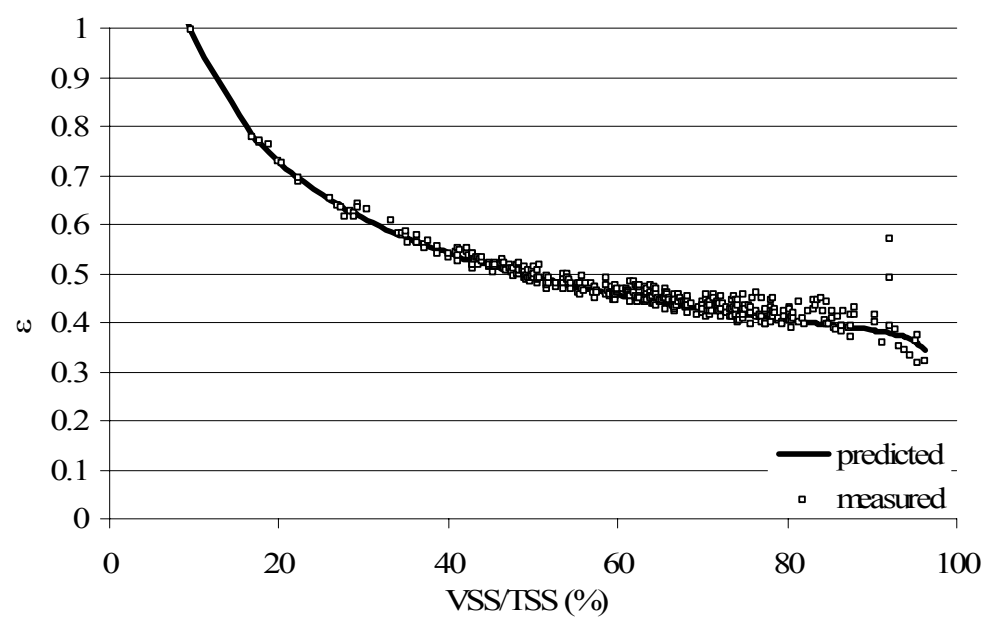

Figure 6. Correlation of sludge bed porosity with VSS/TSS ratio

From all that was mentioned above, it is obvious that the sludge bed porosity of a UASB reactor can be estimated with a simple determination of VSS/TSS ratio.

\section{CONCLUSIONS}

Among all the different types of anaerobic digesters applied at full scale, UASB reactors present the best commercial acceptance. The success of these reactors is related to their capacity for biomass accumulation by settling without the need of a carrier. Good settling 
properties are obtained through the flocculation of the biomass in the form of dense granules with diameters up to several millimetres. The evolution of sludge characteristics is of vital importance for the monitoring of UASB reactors. In this paper, a simple technique for the determination of size distribution was presented. No sophisticated equipment is needed and results can be obtained within a couple of hours. The analysis are completely reproducible, with good precision and exactitude. Small samples of sludge are needed, which is especially important in the case of laboratory scale reactors, where large samples are not available. The proposed technique consists of the determination of the settling velocities of a sludge sample, by the test proposed by Andras et al. (1989) and also used by a number of researchers (Hulshoff Pol, 1989; Laguna et al., 1999; Grothenhuis et al., 1991) and of extrapolating the corresponding diameters using a mathematical algorithm. In the proposed algorithm, the granules were assumed spherical, their density was calculated, the flow regime was examined and finally the granule size distribution was obtained.

The experimental results brought up some important correlations. First, a good correlation between the density and the VSS/TSS ratio of granules was established. The diameter of granules was also correlated with the VSS/TSS ratio. This correlation is a very useful tool for an easy and quick estimation of the granule diameter in a sludge sample. Furthermore, by using a simple algorithm the sludge bed porosity of a UASB reactor can be estimated. Thus, by the simple and routine, even in industrial scale, analysis of TSS and VSS, the characterization of a sludge bed as far as its granulation and porosity are concerned can be easily achieved.

\section{REFERENCES}

1. Andras E., Kennedy K.J. and Richardson D.A. (1989), Test for characterizing settleability of anaerobic sludge, Environmental Technology Letters, 10(5), 463-470.

2. APHA (1985), Standard methods for the examination of water and wastewater, American Public Health Association, Washington DC.

3. Dudley B.T., Howgrave-Graham A.R., Bruton A.G. and Wallis F.M. (1993), Image analysis to quantify and measure UASB digester granules, Biotechnology Bioengineering, 42(3), 279283.

4. Elmaleh S. and Grasmick A. (1985), Mathematical Models For Biological Aerobic Fluidized Bed Reactors, In: Mathematical models in biological wastewater treatment, Jørgensen, S.E. and Gromiec, M.J. (Eds), Elsevier, Netherlands.

5. Grotenhuis J.T.C., Kissel J.C., Plugge C.M., Stams A.J.M. and Zehnder A.J.B. (1991), Role of substrate concentration in particle size distribution of methanogenic granular sludge in UASB reactors, Water Research, 25(1), 21-27.

6. Hulshoff Pol L.W. (1989), The Phenomenon of Granulation of Anaerobic Sludge, Ph.D. Thesis, Wageningen Agricultural University.

7. Jeison D. and Chamy R. (1998), Novel technique for measuring the size distribution of granules from anaerobic reactors for wastewater treatment, Biotechnology Techniques, 12(9), 659-662.

8. Laguna A., Ouattara A., Gonzalez R.O., Baron O., Fama G., El Mamoun R., Guiot S., Monroy O. and Macarie H. (1999), A simple and low cost technique for determining the granulometry of upflow anaerobic sludge blanket reactor sludge, Water Science Technology, 40(8), 1-8.

9. Mahling A.M. (1965), Die Dichte, In: Handbuch der Ledensmittel, Band II, Teil 1, Analytik der Ledensmittel, Schormueller, J. (Eds.), Springer Verlg, BRD.

10. Metcalf \& Eddy (1991), Wastewater Engineering - Treatment, Disposal and Reuse, Third Edition, McGrawHill International Editions, New York.

11. Xu H.L. and Tay J.H. (2001), Preserved granular sludge for inoculation of new UASB reactors, Journal of Environmental Science Health A, 36(9), 1747-1756.

12. Yan Y.G. and Tay J.H. (1997), Characterization of the granulation process during UASB startup, Water Research, 31(7), 1573-1580. 